\title{
Analysis of directive sensor influence on array beampatterns
}

\author{
Lara del Val ${ }^{1}$, Alberto Izquierdoํ, María I. Jiménez ${ }^{1}$, \\ Juan J. Villacorta ${ }^{1}$ and Mariano Raboso ${ }^{2}$ \\ ${ }^{1}$ Universidad de Valladolid (Departamento de Teoría de la Señal y Comunicaciones e \\ Ingeniería Telemática) \\ Spain \\ ${ }^{2}$ Universidad Pontificia de Salamanca (Escuela Universitaria de Informática) \\ Spain
}

\section{Introduction}

Over the past few years, a large number of pattern synthesis techniques of antenna arrays have been studied and developed. Such techniques may be classified into two categories: techniques that optimize the excitation (amplitude and phase) of each element in a uniform array (Van Veen \& Buckley, 1988), and techniques that adjust the positions of the elements with uniform excitation, resulting in a non-uniform geometry ("Unz, 1960", "Harrington, 1961", "Skolnik et al., 1964", "Haupt, 1994"). Despite of this classification, both categories are not exclusive; so, it is possible to develop techniques that optimize both the excitations and the positions of the elements ("Akdagli \& Guney, 2003", “Kurup et al., 2003", "Kumar \& Branner, 2005").

It has been also observed that many of these techniques make a beampattern synthesis only in the case of an array pointing to the broadside. Only a few techniques are designed taking into account other angles further than the broadside ("Bae et al., 2005", "Bray et al., 2002", "Feng \& Chen, 2005"), which is the basis of beamforming. The reason is that, these techniques work on the assumption that the array is formed by omnidirectional sensors. In this case, working with the array pattern in the $u$ domain $(u=\operatorname{sen}(\theta))$, a variation of the pointing angle only implies that a shift in the beampattern, without variation of the characteristics of neither the main lobe, nor the sidelobes (Mailloux, 2005). Thus, representing the pattern in the $\mathrm{u}-\mathrm{u}_{0}$ domain $\left(\operatorname{sen}(\theta)-\operatorname{sen}\left(\theta_{0}\right)\right.$, being $\theta_{0}$ the pointing angle), implies that a variation in the steering angle does not produce any effect on the array beampattern.

The problem arises when the assumption that sensors forming the array are omnidirectional can not be used. There are different types of arrays that employ directive sensors, such as retro-directive (Feng \& Chen, 2005), or acoustic arrays (Brandstein \& Ward, 2001). In these cases, design methods of array pattern synthesis based on pointing only to the broadside, are not suitable techniques if these arrays are going to be used in beamforming systems 
later, because there is no information about the behaviour of the array pointing to angles that are different of the broadside.

The purpose of this paper is to study the influence of the sensor directivity into the array beampattern, in order to test if its effects on the array pattern must be taken into consideration in design methods of pattern array synthesis, and other array design methods. This chapter is organized so that the next section describes the studies accomplished for the analysis, as well as the results found. Finally, some interesting conclusions are shown in section 3.

\section{Analysis Results}

A linear array with 19 uniformly spaced sensors has been used in this study. The spacing between sensors can vary between $\lambda / 4$ and $\lambda$. With these spacing we avoid the effects of mutual coupling (Agrawal \& Lo, 1972). As this work is based on linear arrays, beampatterns are only represented in azimuth $(\theta)$.

The range of variation of $\theta$ is $\left[-90^{\circ}, 90^{\circ}\right]$ with one degree steps. The diagram is represented in the $u$ domain, so the range of azimuth values really is $[-1,1]$.

This analysis has been carried out employing sensors with a cardioid directive response, which is the most frequently directive response for audio microphones, and working under the assumption that all sensors have the same directive response. This assumption can be done because there are not mutual coupling effects. The employed formula is:

$$
D=[1 /(1+C)] \cdot(C+\cos \theta)
$$

In this study values of constant $C$, which has been named Directive Factor, have been varied from 0.25 (most sharp cardioid) to 1 (less sharp cardioid).

A deep analysis of the invariance of ULA beampattern versus the steering angle has been made, using spacing value of $\lambda / 2$ of and with a directive factor $C$ with a 1.0 value, verifying that the hypothesis of invariance is not fulfilled with directive sensors. Beampattern for a maximum steering angle, $\theta_{0}$, of $\pm 60^{\circ}$ is evaluated.

Figure 1 shows beampatterns for different positive steering angles $\theta_{0}$, where the $x$-axis, corresponds to variable $\mathrm{u}-\mathrm{u}_{0}$, being $\mathrm{u}=\sin \theta$ and $\mathrm{u}_{0}=\sin \theta_{0}$. When steering angle increases from broadside, the contribution of the directive sensors on the beampattern is stronger. This contribution does not affect on the same way to positive and negative $\mathrm{u}-\mathrm{u}_{0}$ values. For positive $u-u_{0}$ values, when the steering angle increases, sidelobes of the beampattern decrease, improving array performance. For $\mathrm{u}$ - $\mathrm{u}_{0}$ negative values, beampattern sidelobes increase, reducing array performance.

Besides this behaviour difference between positive and negative $\left|\mathrm{u}-\mathrm{u}_{0}\right|$ values, another two effects of sensor directivity on array beampattern can be observed:

(a) As the steering angle $\left(\theta_{0}\right)$ moves away from the broadside, sensor directivity leads to a higher increase of sidelobe level. This effect can be observed in Figure 2, where the seventh sidelobe on the left of the mainbeam for several steering angles are shown. 


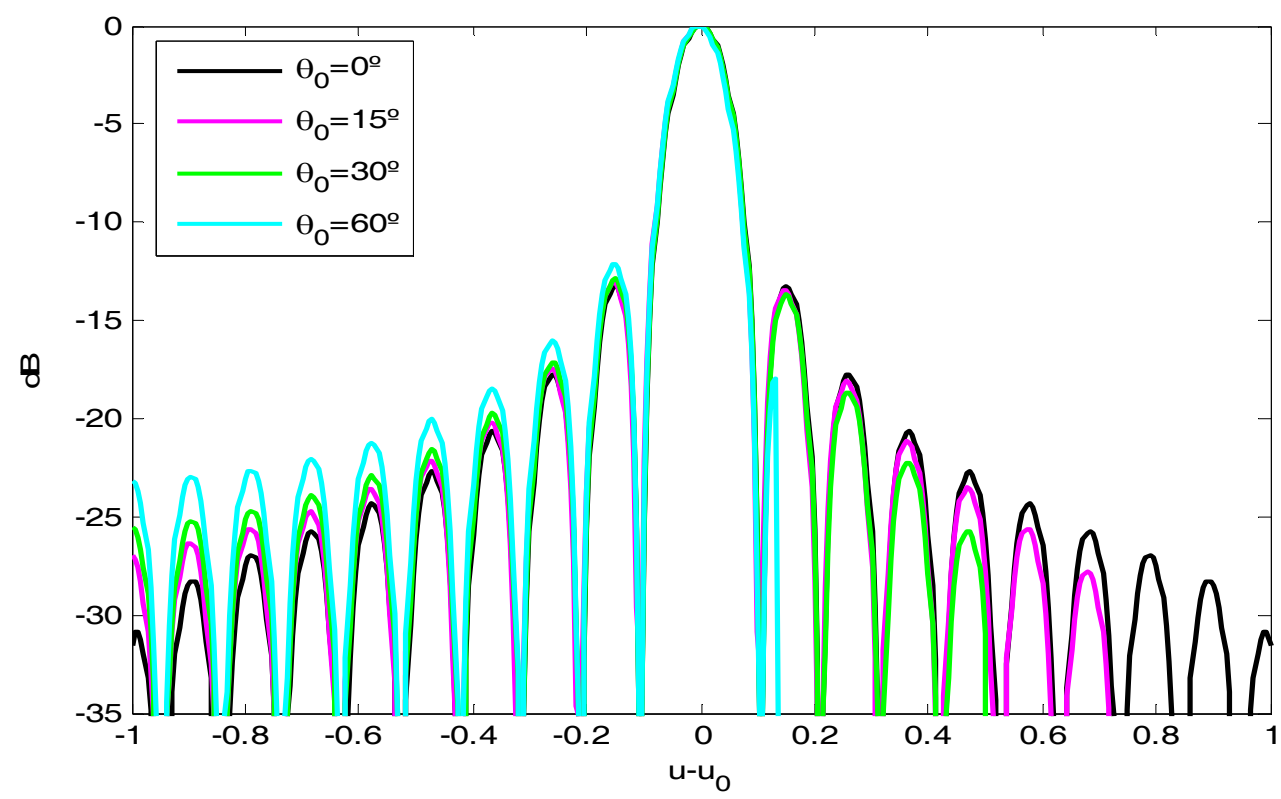

Fig. 1. ULA beampattern in $\mathrm{u}-\mathrm{u}_{0}$ space with cardioid sensors

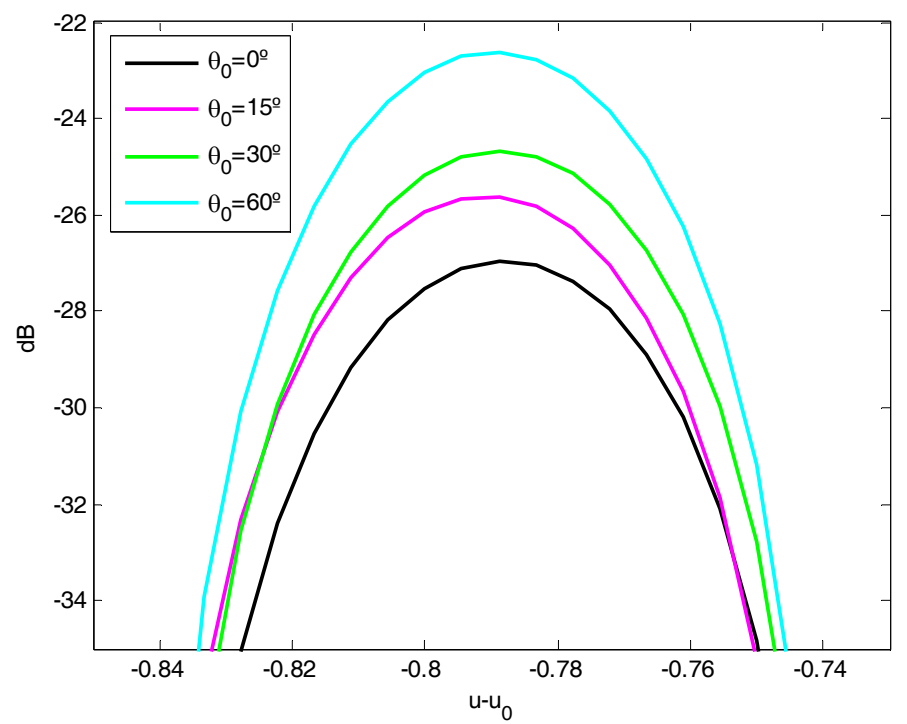

Fig. 2. Sensor directivity effect vs. Steering angle $\theta_{0}$

(b) For a constant $\theta_{0}$ value, as $\left|\mathrm{u}-\mathrm{u}_{0}\right|$ comes to 1 , sensor directivity influence is higher, increasing the difference between the omnidirectional and the directive cases. This effect is 
shown in Figure 3, where the beampatterns of the omnidirectional and the directive cases for $\theta_{0}=0$ are shown as an example.

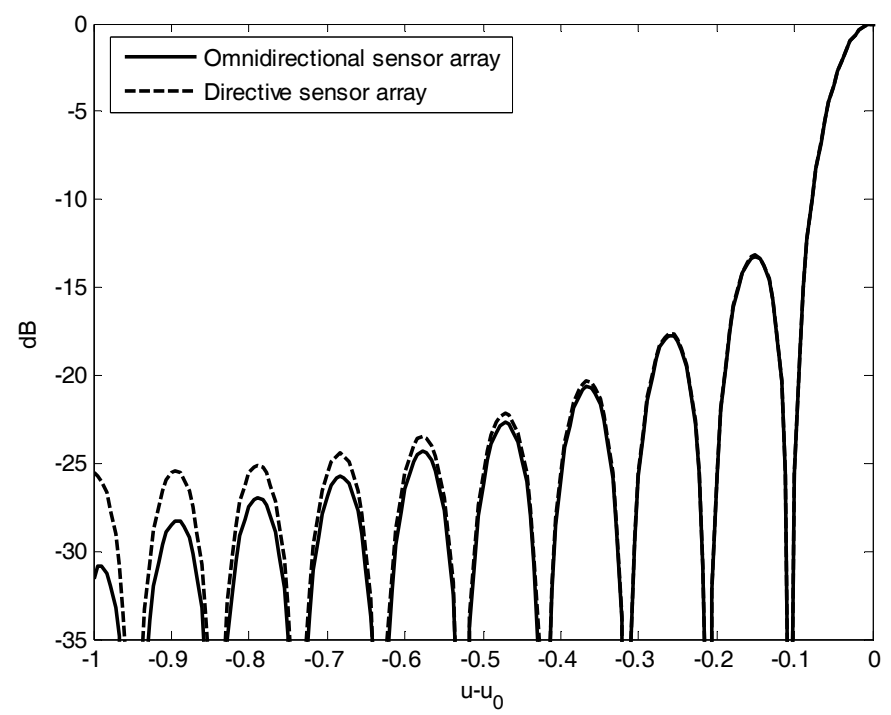

Fig. 3. Sensor directivity effect vs. $\left|\mathrm{u}-\mathrm{u}_{0}\right|$

In order to characterize absolute variation of sidelobe levels, $\triangle S L L_{i}$ has been defined:

$$
\Delta S L L_{i}=S L L_{i}\left(\theta_{0}=60^{\circ}\right)-S L L_{i}\left(\theta_{0}=0^{\circ}\right)
$$

Table 1 shows the absolute variation of the 8 first sidelobes located on the left of the mainlobe. It can be observed that moving away from the mainlobe (increasing index i), the variation of the sidelobe level increases. For the fifth sidelobe, $\triangle S L L$ is greater than $3 \mathrm{~dB}$.

\begin{tabular}{|l|l|l|l|l|l|l|l|l|}
\hline $\mathrm{i}$ & 1 & 2 & 3 & 4 & 5 & 6 & 7 & 8 \\
\hline$\Delta \mathrm{SLL}_{\mathrm{i}}$ & 1.51 & 1.67 & 2.16 & 2.63 & 3.11 & 3.65 & 4.25 & 5.16 \\
\hline
\end{tabular}

Table 1. $\triangle S L L_{i}(\mathrm{~dB})$ for the 8 sidelobes on the left of the mainlobe

This section continues with detailed studies for several sidelobe levels, where dependences on the steering angle, sensor spacing and directive factor $\mathrm{C}$ are analyzed.

\subsection{First Sidelobe Level $\left(S_{L} L_{1}\right)$}

\section{$\mathrm{SLL}_{1}$ Sensitivity vs. steering angle}

Figure 4 shows that increasing steering angles produce higher first sidelobe levels, at the left of the mainlobe. For small steering angles, the first sidelobe level is below the omnidirectional case, but with greater angles the sidelobe level exceeds the omnidirectional one. The reason of this behaviour is that pointing the beam more and more to the right, i.e. 
increasing the steering angle, makes beampattern values on the left of the mainbeam be affected by lower and lower sensor directivity values, as it is showed in Figure 5. The effect of sensor directivity over the first sidelobe can vary its level in $1.52 \mathrm{~dB}$.

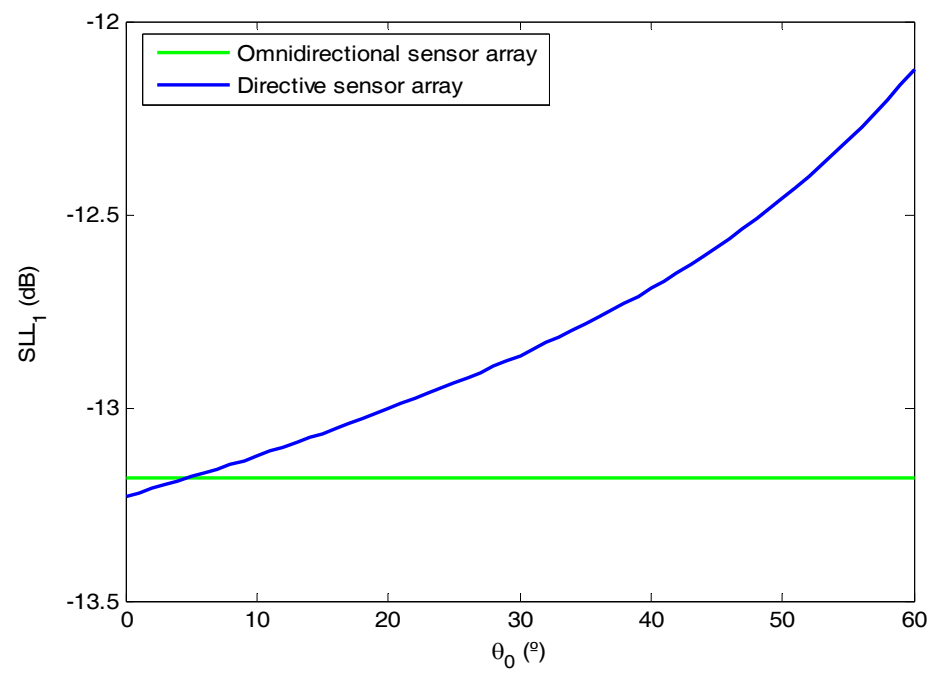

Fig. 4. Left $\mathrm{SLL}_{1}$ vs. Steering angle

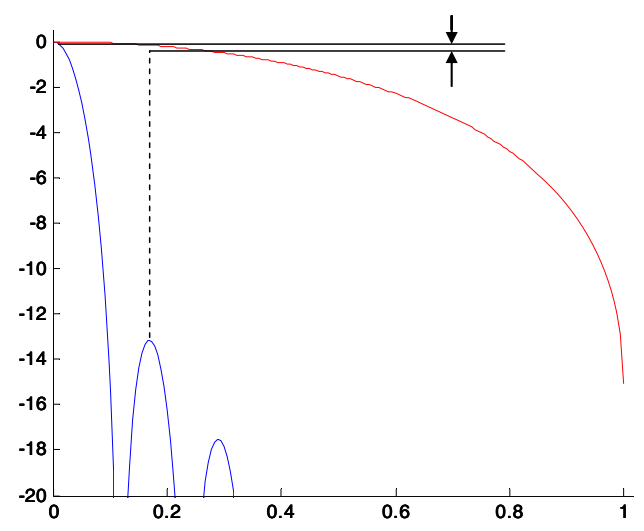

a)

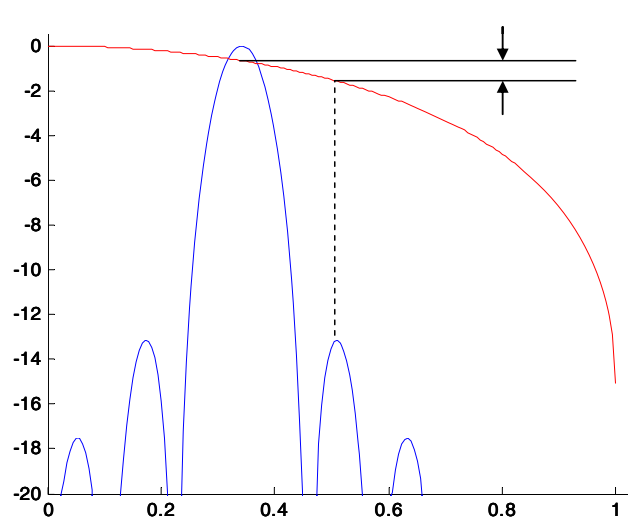

b)

Fig. 5. Sensor directivity effect on first sidelobe level. Spacing $=\lambda / 2$. a) $\theta_{0}=0^{\circ}$, b) $\theta_{0}=20^{\circ}$

\section{SLL $_{1}$ Sensitivity vs. sensor spacing:}

This first sidelobe level analysis is extended with a study of sensor directivity influence on array beampattern with regard to sensor spacing. This spacing is varied between $0.25 \lambda$ and $1 \lambda$. Directive factor $(\mathrm{C})$ is fixed to 1 . Figure 6 shows this influence with regard to sensor spacing. It can be observed that an increase on sensor spacing deals to a SLL decrease. 


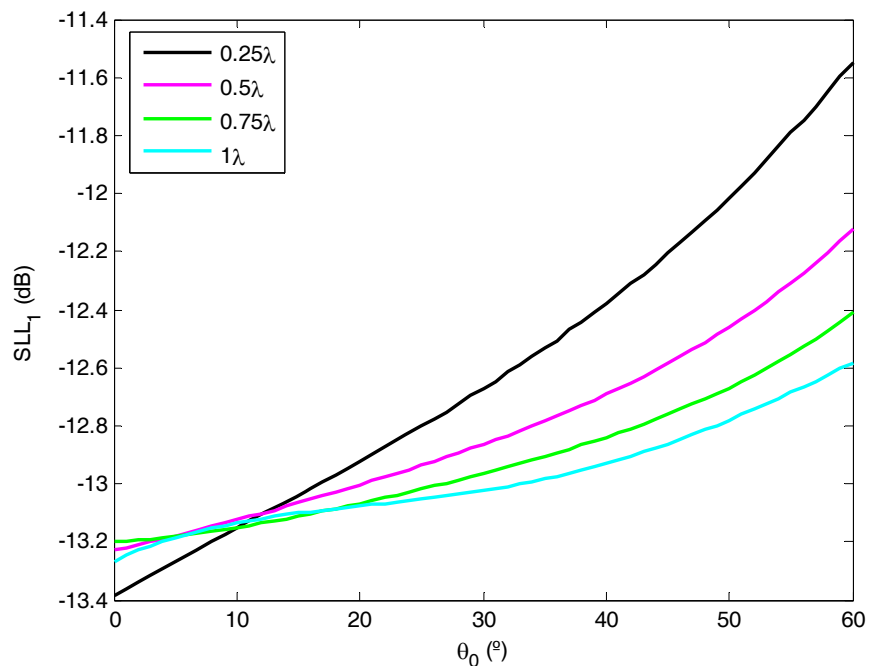

Fig. 6. SLL 1 vs. Steering angle $\left(\theta_{0}\right)$ for several sensor spacing. $C=1$.

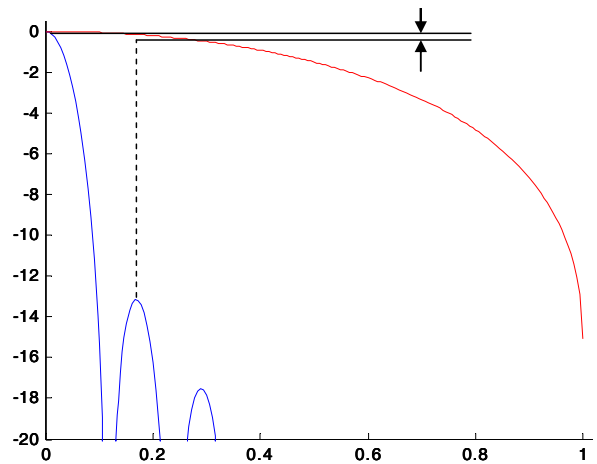

a)

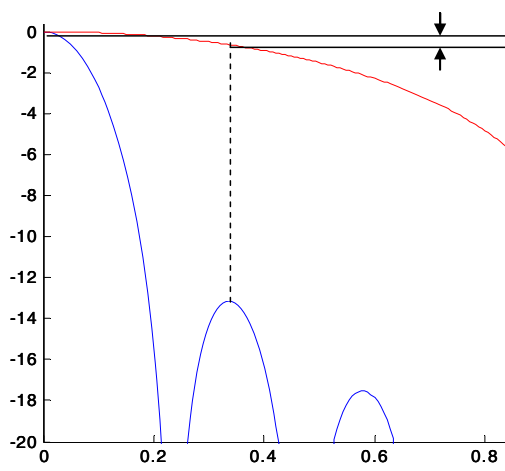

c)

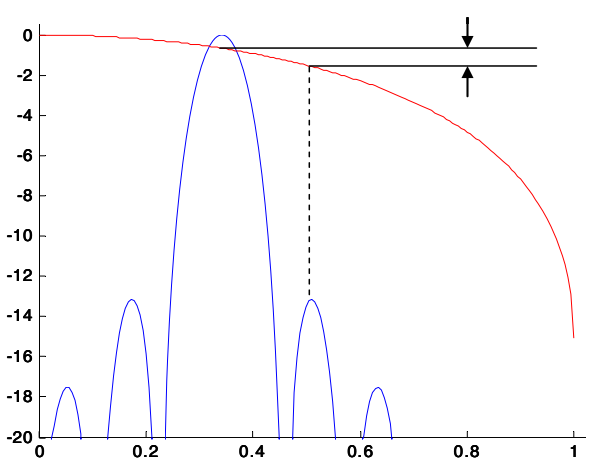

b)

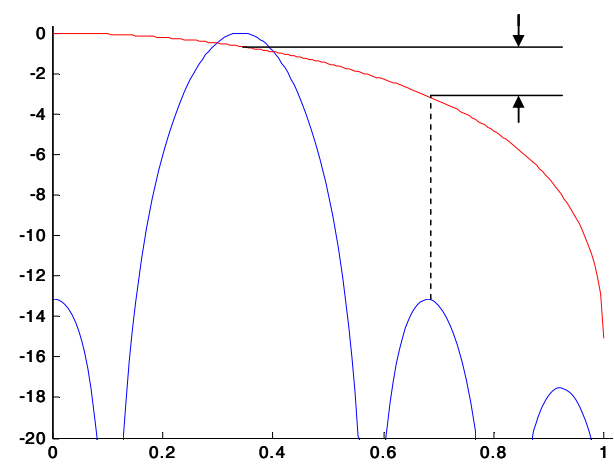

d)

Fig. 7. Sensor directivity effect on first sidelobe level. $C=1$. a) Spacing $=\lambda / 2$ and $\theta_{0}=0^{\circ}$; b) Spacing $=\lambda / 2$ and $\theta_{0}=20^{\circ}$; c) Spacing $=0.25 \lambda$ and $\theta_{0}=0^{\circ}$; d) Spacing $=0.25 \lambda$ and $\theta_{0}=20^{\circ}$ 
The reason of this behaviour is that increasing sensor spacing makes a compression of the beampattern. Figure 7 shows how the first sidelobe is closer and closer to the mainbeam, reducing the difference between the directivity values that affects each of these lobes (first sidelobe and mainlobe).

The variation of $\mathrm{SLL}_{1}\left(\Delta \mathrm{SLL}_{1}\right)$ is inversely proportional to sensor spacing, as it can be observed in Figure 8 . The sensitivity of $\Delta \mathrm{SLL}_{1}$ versus sensor spacing is lower than the one on steering angle. This effect must be taken into account, since it can increase sidelobe level between $0.68 \mathrm{~dB}$ and $1.81 \mathrm{~dB}$, i.e. a $1.13 \mathrm{~dB}$ variation.

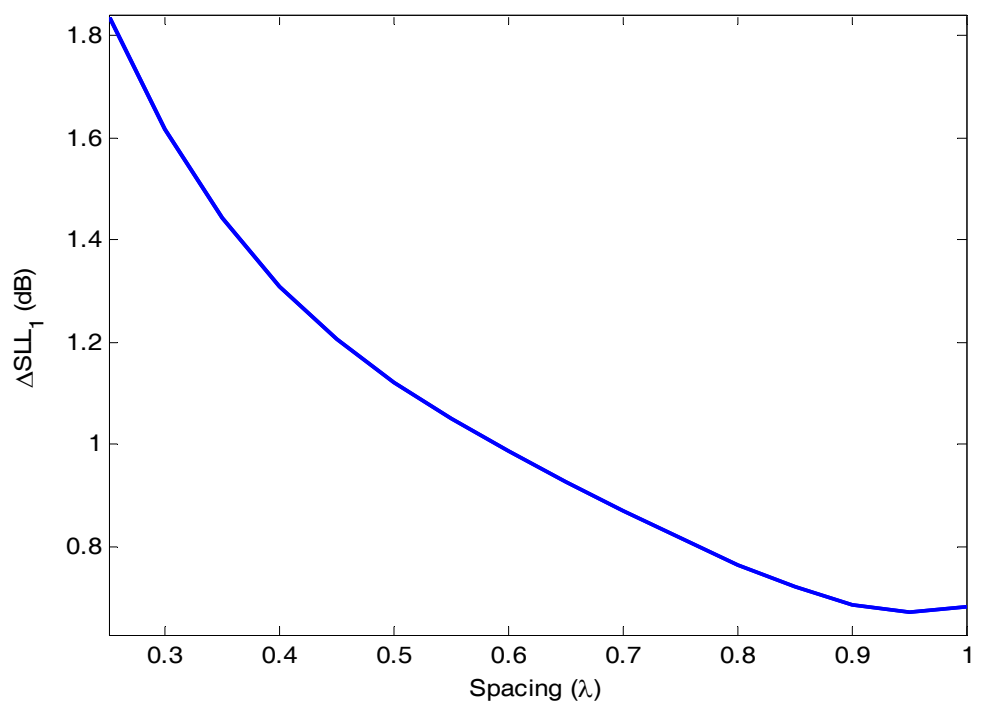

Fig. 8. $\Delta S L L_{1}$ vs. Sensor spacing

\section{$\mathrm{SLL}_{1}$ Sensitivity vs. Directive factor C}

SLL $_{1}$ analysis is finished off with a study of sensor directivity influence on the array beampattern with regard to sensor directive factor (C). This directivity factor is varied between 1 and 0.25 . Sensor spacing is fixed to $0.5 \lambda$. Figure 9 shows this influence. It can be observed that decreasing directive factor, i.e. using more directive sensors, increases SLL 1 . The reason of this behaviour is that sharper sensor directivity deals to a larger difference between the directivity values that affect first sidelobe and mainlobe, as Figure 10 shows.

The variation of $\mathrm{SLL}_{1}\left(\Delta S L_{1}\right)$, is inversely proportional to the directive factor, as it can be observed in Figure 11. The sensitivity of $\mathrm{SLL}_{1}$ versus directive factor is lower than the sensitivity versus sensor spacing. In this case, the effect can be increased from $1.11 \mathrm{~dB}$ to $2.03 \mathrm{~dB}$, i.e. a $0.92 \mathrm{~dB}$ variation.

These SLL $L_{1}$ analyses show that $\mathrm{SLL}_{1}$ is less sensitive to directive factor variations than to spacing and steering angle ones. The highest sensitivity is shown for the steering angle.

All these analyses have been done for positive steering angles. In the case of negative steering angles values, the behaviour would be the symmetric one. 


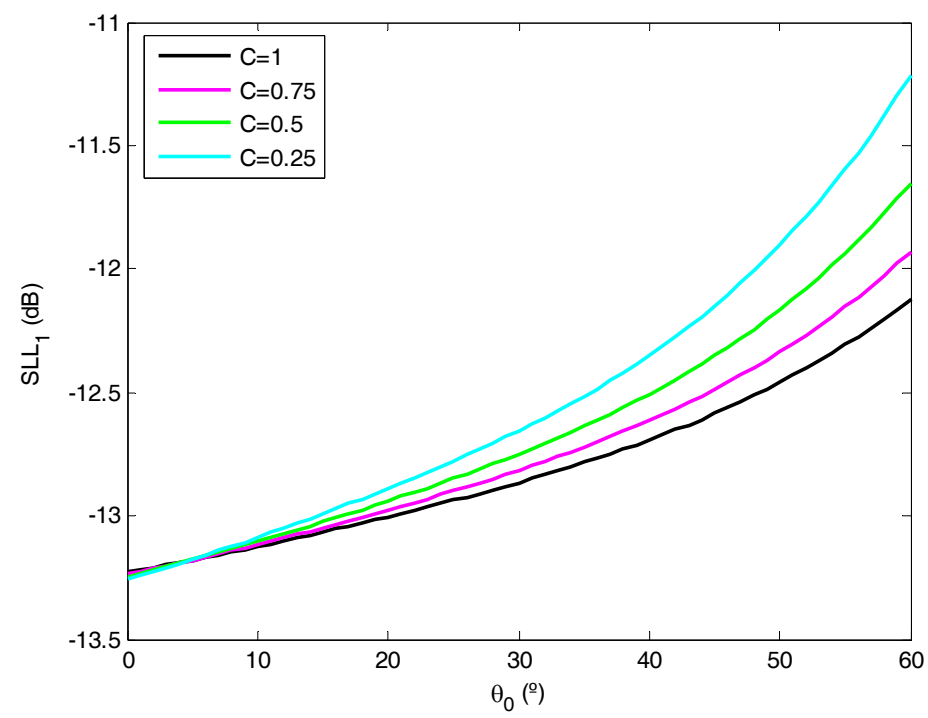

Fig. 9. SLL 1 vs. Steering angle $\left(\theta_{0}\right)$ for several directive factors $(C)$. Spacing $=\lambda / 2$.

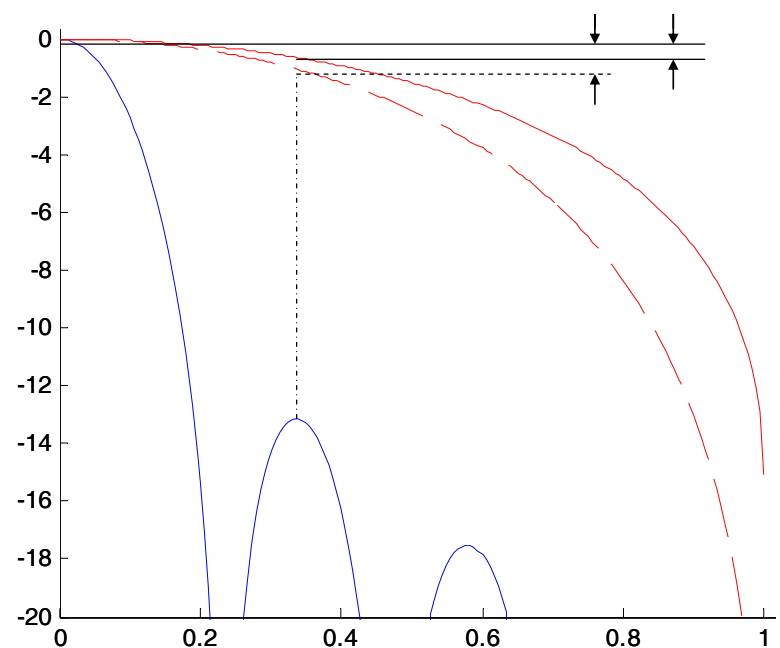

Fig. 10. Sensor directivity effect on first sidelobe level. Spacing $=\lambda / 2$. $C=1(\ldots), C=0.25$ ( - - ) 


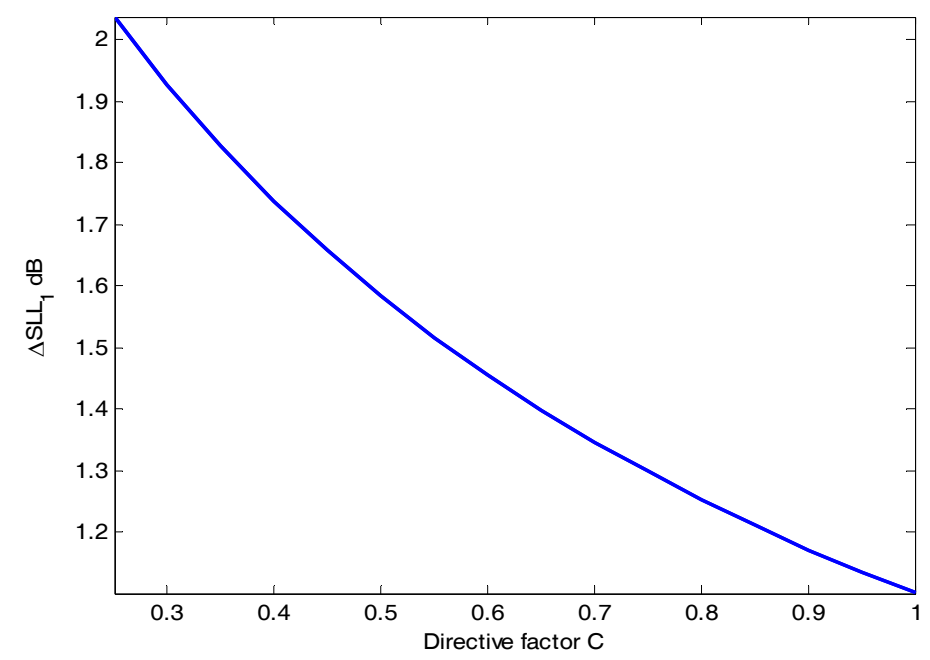

Fig. 11. $\Delta \mathrm{SLL}_{1}$ vs. Directive factor $\mathrm{C}$

\subsection{Sidelobe Average Level ( $\overline{S L L}$ )}

The analysis of the average sidelobe level $(\overline{S L L})$ is similar to the analysis of the first sidelobe level. A sidelobe average level that calculates the average of the first 8 sidelobes on the left of the mainlobe has been taken in consideration. This average level of an array formed by omnidirectional sensors is constant.

Figure 12 shows that, an increase in steering angle causes an increase in $\overline{S L L}$. Firstly, the average level values for the directional case are below the values of the omnidirectional case, but with an increasing steering angle, average level values of the directional case are over the omnidirectional ones. This average level has a variation $(\triangle \overline{S L L})$ of $3.75 \mathrm{~dB}$.

The analyses of the $\overline{S L L}$ sensibility versus sensor spacing and directive factor $(\mathrm{C})$, have been made in the same way than the ones shown for $\mathrm{SLL}_{1}$. In this case, an increase on the spacing and/or on the directive factor, also means a decrease of $\triangle \overline{S L L}$, as it can be observed in Figures 13 and 14 .

For this sidelobe level, the sensitivity of $\triangle \overline{S L L}$ versus sensor spacing is also lower than the one versus steering angle. Despite this sensitivity is lower, it must be taken into consideration, since it can increase average sidelobe level between $4.48 \mathrm{~dB}$ and $6.51 \mathrm{~dB}$, i.e. a $2.17 \mathrm{~dB}$ variation.

The sensitivity of $\triangle \overline{S L L}$ versus directive factor is also lower than the sensitivity versus steering angle. In this case, the effect can be increased from $5.52 \mathrm{~dB}$ to $7.60 \mathrm{~dB}$, i.e. a $2.08 \mathrm{~dB}$ variation.

These analyses show that $\overline{S L L}$ is more sensitive to directive factor variations than to spacing and steering angle ones. The highest sensitivity, as in the SLL 1 analysis, is shown for the steering angle. 


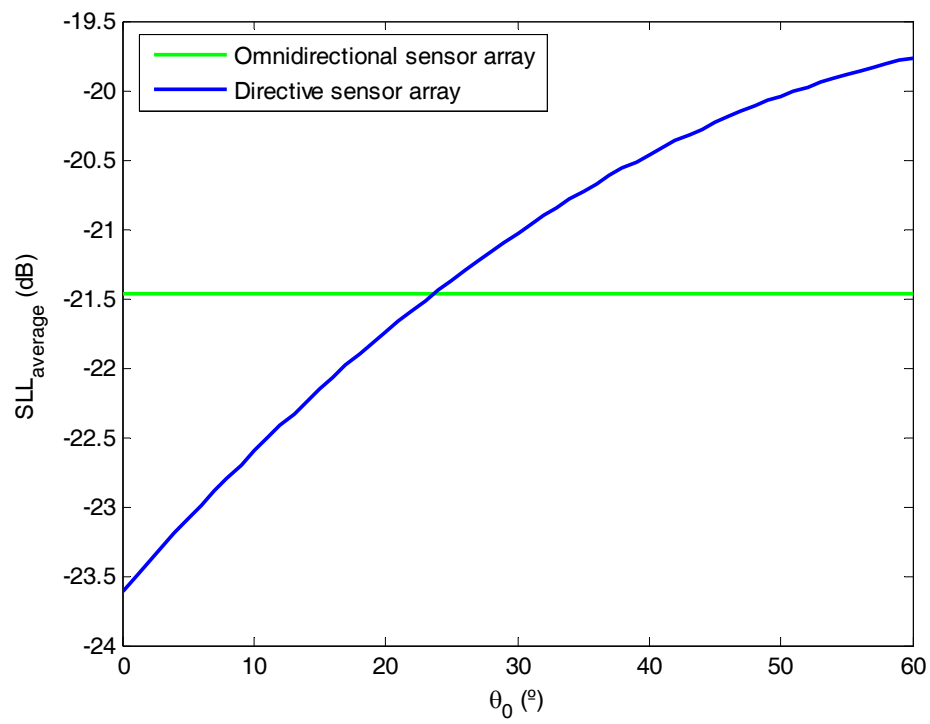

Fig. 12. $\overline{S L L}$ vs. Steering angle

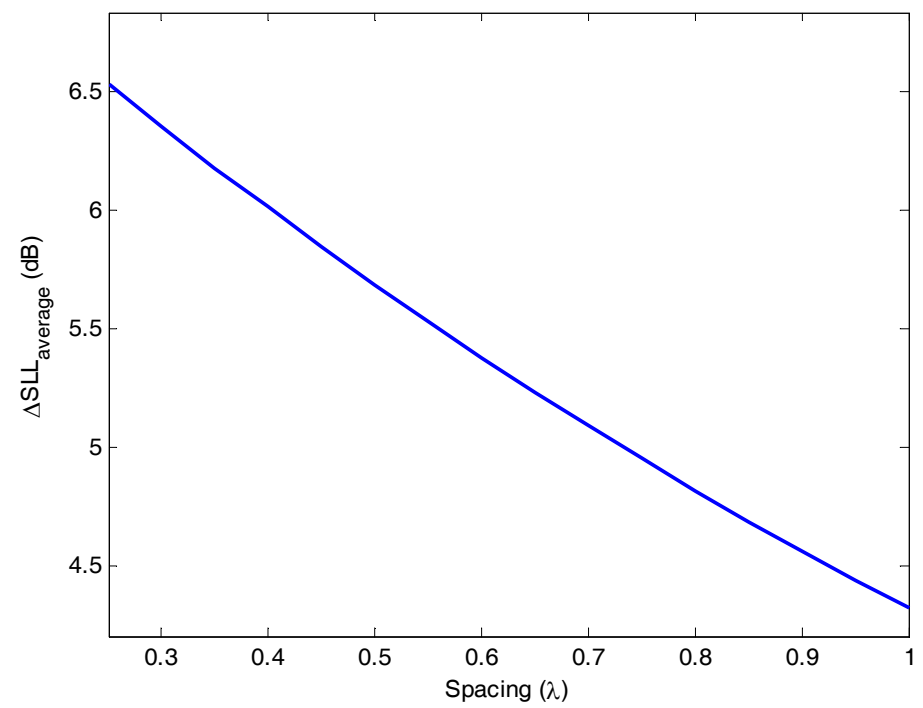

Fig. 13. $\Delta \overline{S L L}$ vs. Sensor spacing 


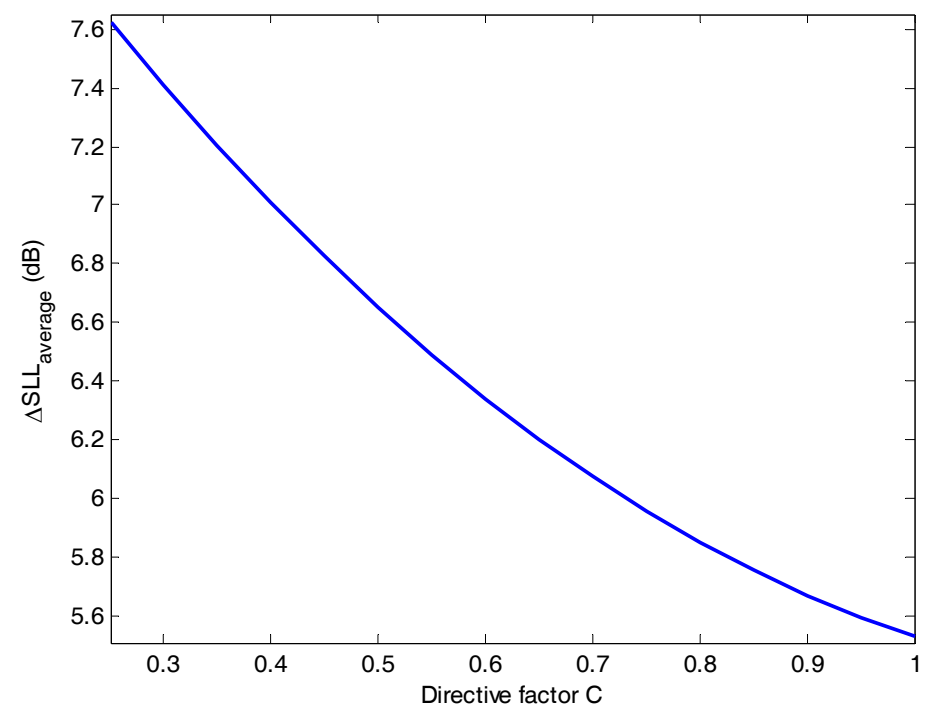

Fig. 14. $\Delta \overline{S L L}$ vs. Directive Factor C

\subsection{Maximum Sidelobe Level (SLL $\left.{ }_{\max }\right)$}

Lastly, maximum sidelobe level (SLLmax), which is related with grating lobes, is analysed. Due to the appearance of grating lobes depends on sensor spacing, the influence of this spacing on the variation of SLL max and steering angle is studied. Figure 15 shows that an increase of steering angle means an increase of SLLmax for all spacing.

For spacing greater than $\lambda / 2$, there are two different behaviours:

(a) A first one, with SLLmax around $-13 \mathrm{~dB}$ that grows up slowly with increasing steering angle.

(b) A second one, where SLL $\max$ suffers a quite abrupt increase. This increase indicates the existence of grating lobes.

For $\lambda$ spacing, the behaviour is again unique, because there are grating lobes for all the steering angles.

Comparing Figures 15 and 16, where SLL $\max$ performance for an omnidirectional sensor array is shown, it can be observed that the sensor directive response makes grating lobes appearance more gradual and less abrupt than in the omnidirectional case. This is an improvement in array performance, but it is also a problem because it can be even greater than the mainlobe. 


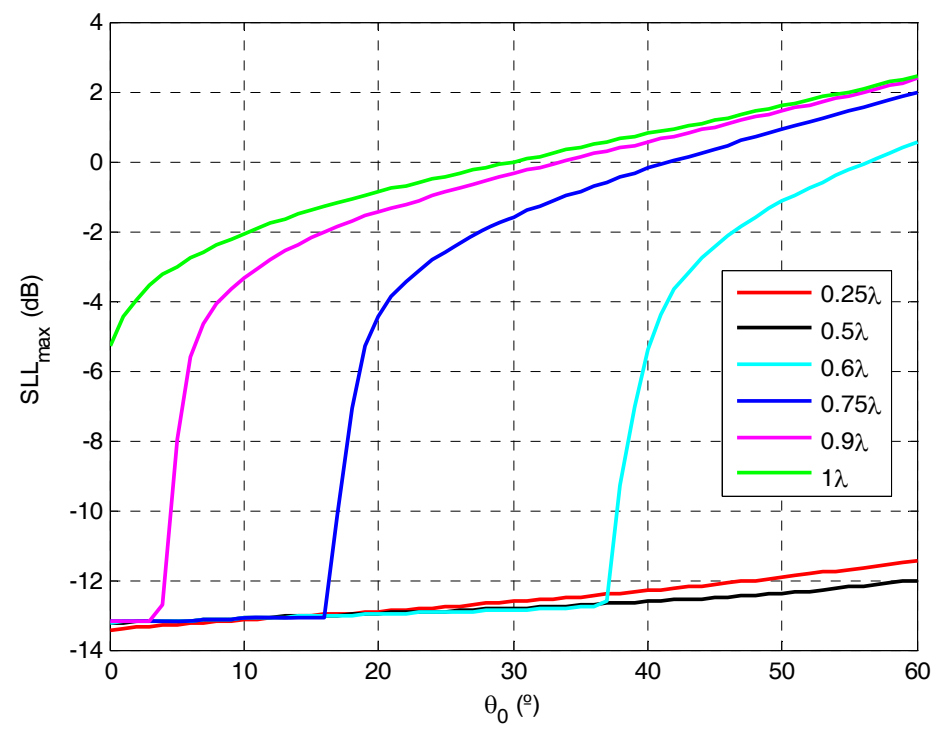

Fig. 15. $\mathrm{SLL}_{\max }$ vs. Steering angle for several sensor spacing. $\mathrm{C}=1$. Directive sensor array

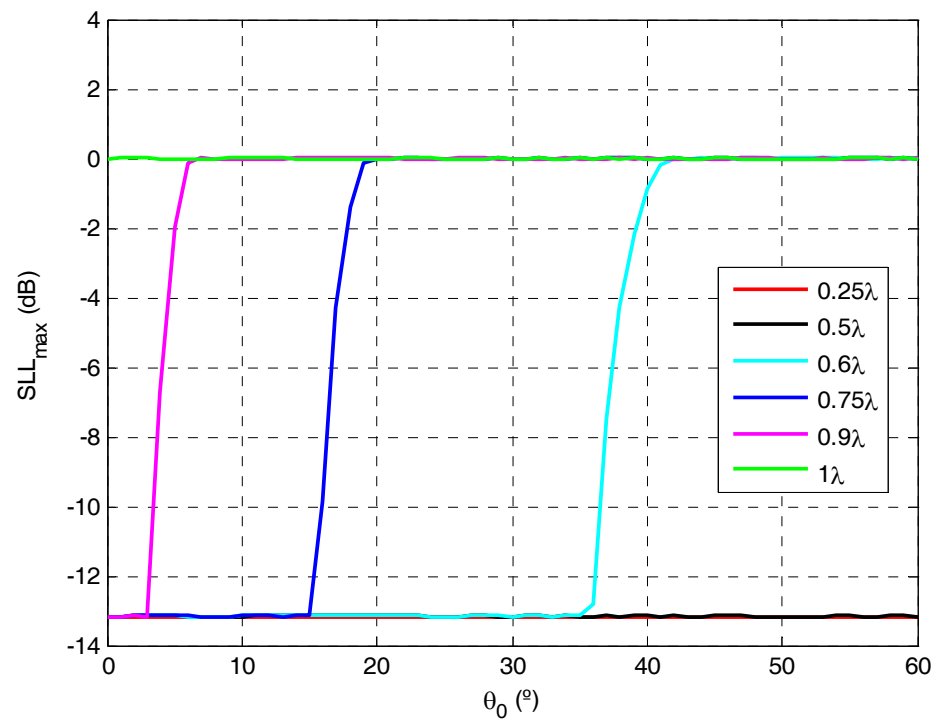

Fig. 16 SLLmax vs. Steering angle for several sensor spacing. Omnidirectional sensor array

\section{Conclusions}

This paper shows that using arrays with directive sensors makes the invariance hypothesis no longer valid. Sidelobe level increments around $5 \mathrm{~dB}$ can be observed if directive sensors 
are used. This effect can be increased depending on the sensor spacing and the directive factor.

In Table 2, $\triangle S L L_{1}$ and $\triangle \overline{S L L}$ versus steering angle, spacing and directive factor relations are shown. Sidelobes are more sensitive to steering angle variation than to spacing and directive factor variation. $\overline{S L L}$ is more sensitive to parameter variation than $\mathrm{SLL}_{1}$, because $\overline{S L L}$ includes effects on several sidelobes, and these effects are larger in sidelobes which are more distant from the main lobe. $\overline{S L L}$ is also more sensitive because it includes grating lobes effect. This effect is also included in maximum sidelobe level. Sensor directivity produces a more gradual appearance of greater grating lobes.

\begin{tabular}{|l|c|c|}
\cline { 2 - 3 } \multicolumn{1}{c|}{} & $\Delta S L L_{1}[\mathrm{~dB}]$ & $\Delta \overline{S L L}[\mathrm{~dB}]$ \\
\hline Steering angle & 1.51 & 3.22 \\
\hline Sensor spacing & 1.13 & 2.17 \\
\hline Directive factor $(\mathrm{C})$ & 0.92 & 2.08 \\
\hline
\end{tabular}

Table 2. $\Delta S L L_{1}$ and $\Delta \overline{\overline{S L L}}$ vs. steering angle, spacing and directive factor (C)

The research has been realized for sensors whose directive response is a cardioids function, but it can be extended as a future work to any other type of directive response. It can be also extended to random arrays, because they are influenced by the sensor directive response.

\section{References}

A. Akdagli, and K. Guney (2003). Shaped-Beam Pattern Synthesis of Equally and Unequally Spaced Linear Antenna Arrays Using a Modified Tabu Search Algorithm, Microwave and Optical Technology Letters, Vol. 36, No. 1, (Jan. 2003) 16-20, ISSN 0895 2477

V. Agrawal and Y. Lo (1972). Mutual coupling in phased arrays of randomly spaced antennas, IEEE Transactions on Antennas and Propagation, Vol. AP-20, No. 3, (May 1972) 288-295, ISSN 1045-9243

J. Bae, K. Kim, and C. Pyo (2005). Design of Steerable Linear and Planar Array Geometry with Non-uniform Spacing for Side-Lobe Reduction, IEICE Transactions on Communications, Vol. E88-B, No. 1, (Jan. 2005) 345-357, ISSN 0916-8516

M. Brandstein, and D. Ward (2001). Microphone Arrays. Signal Processing Techniques and Applications, Springer-Verlag, ISBN 3-540-41953-5, Berlin

M. Bray, D. Werner, D. Boeringer, and D. Machuga (2002). Optimization of Thinned Aperiodic Linear Phased Arrays Using Genetic Algorithms to Reduce Grating Lobes During Scanning, IEEE Transactions on Antennas and Propagation, Vol. 50, No. 12, (Dec. 2002) 1732-1742, ISSN 1045-9243

B. Feng, and Z. Chen (2004). Optimization of Three Dimensional Retrodirective Arrays, Proceedings of the IEEE 3rd Annual Communication Networks and Services Research Conference 2005, pp. 80-83, ISBN 0-7695-2333-1, Halifax (Nova Scotia, Canada), May 2005, Halifax

R. Harrington (1961). Sidelobe reduction by nonuniform element spacing, IRE Transactions on Antennas and Propagation, Vol. 9, No. 2, (Mar. 1961) 187-192, ISSN 0096-1973 
R. Haupt (1994). Thinned arrays using genetic algorithms, IEEE Transactions on Antennas and Propagation, Vol. 42, No. 7, (May 1994) 993-999, ISSN 1045-9243

B. Kumar, and G. Branner (2005). Generalized Analytical Technique for the Synthesis of Unequally Spaced Arrays with Linear, Planar, Cylindrical and Spherical Geometry, IEEE Transactions on Antennas and Propagation, Vol. 53,No. 2, (Feb. 2005) 621-634, ISSN 1045-9243

D. Kurup, M. Himdi, and A. Rydberg (2003). Synthesis of Uniform Amplitude Unequally Spaced Antenna Arrays Using the Differential Evolution Algorithm, IEEE Transactions on Antennas and Propagation, Vol. 51, No. 9, (Sep. 2003) 2210-2217, ISSN $1045-9243$

R. Mailloux (2005). Phased Array Antenna Handbook (2nd Ed.), Artech House Inc., ISBN 9781580536905, Norwood, MA

M. Skolnik, G. Nemhauser, and J. Sherman (1964). Dynamic programming applied to unequally spaced arrays, IEEE Transactions on Antennas and Propagation, Vol. AP-12, No. 1, (Jan. 1964) 35-43, ISSN 1045-9243

H. Unz (1960). Linear arrays with arbitrarily distributed elements, IRE Transactions on Antennas and Propagation, Vol. 8, No. 2, (Mar. 1960) 222-223, ISSN 0096-1973

B. Van Veen, and K. Buckley (1988). Beamforming: A Versatile approach to Spatial Filtering, IEEE ASSP Magazine, (Apr. 1988) 4-24 


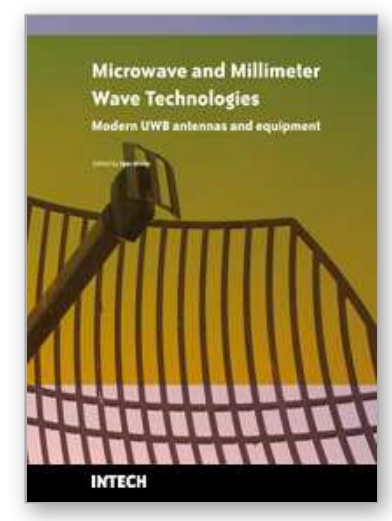

\section{Microwave and Millimeter Wave Technologies Modern UWB antennas and equipment}

Edited by Igor Mini

ISBN 978-953-7619-67-1

Hard cover, 488 pages

Publisher InTech

Published online 01, March, 2010

Published in print edition March, 2010

\section{How to reference}

In order to correctly reference this scholarly work, feel free to copy and paste the following:

Lara del Val, Alberto Izquierdo, Maria I. Jimenez, Juan J. Villacorta and Mariano Raboso (2010). Analysis of Directive Sensor Influence on Array Beampatterns, Microwave and Millimeter Wave Technologies Modern UWB antennas and equipment, Igor Mini (Ed.), ISBN: 978-953-7619-67-1, InTech, Available from: http://www.intechopen.com/books/microwave-and-millimeter-wave-technologies-modern-uwb-antennas-andequipment/analysis-of-directive-sensor-influence-on-array-beampatterns

\section{INTECH}

open science | open minds

\section{InTech Europe}

University Campus STeP Ri

Slavka Krautzeka 83/A

51000 Rijeka, Croatia

Phone: +385 (51) 770447

Fax: +385 (51) 686166

www.intechopen.com

\section{InTech China}

Unit 405, Office Block, Hotel Equatorial Shanghai

No.65, Yan An Road (West), Shanghai, 200040, China

中国上海市延安西路65号上海国际贵都大饭店办公楼 405 单元

Phone: +86-21-62489820

Fax: +86-21-62489821 
(C) 2010 The Author(s). Licensee IntechOpen. This chapter is distributed under the terms of the Creative Commons Attribution-NonCommercialShareAlike-3.0 License, which permits use, distribution and reproduction for non-commercial purposes, provided the original is properly cited and derivative works building on this content are distributed under the same license. 